Type of Paper Review

\title{
Widening inborn constraints for language ability: the case for autism
}

\section{Laurent Mottron ${ }^{1, *}$, Alexia Ostrolenk ${ }^{2}$, David Gagnon ${ }^{3}$}

${ }^{1}$ University of Montreal, Psychiatry and Addictology Department, 2900 blvd EdouardMontpetit, Montreal, QC Canada H3T 1J4; CIUSSS-NIM, Riviere-des-Prairies Hospital, 7070 blvd Perras, Montreal, QC Canada H1E 1A4; laurent.mottron@gmail.com

${ }^{2}$ University of Montreal, Psychiatry and Addictology Department, 2900 blvd EdouardMontpetit, Montreal, QC Canada H3T 1J4; CIUSSS-NIM, Riviere-des-Prairies Hospital, 7070 blvd Perras, Montreal, QC Canada H1E 1A4; alexiaostrolenk@ gmail.com

${ }^{3}$ University of Montreal, Psychiatry and Addictology Department, 2900 blvd EdouardMontpetit, Montreal, QC Canada H3T 1J4; CIUSSS-NIM, Riviere-des-Prairies Hospital, 7070 blvd Perras, Montreal, QC Canada H1E 1A4; gagnon_david@hotmail.com

* Correspondence: Laurent.mottron.cnmtl@ ssss.gouv.qc.ca; Tel: 1-514-972-4841

\begin{abstract}
What does the way autistics bypass, learn, and eventually master language tell us about human linguistic ability? Here, we argue that non-social acquisition of language, in addition to representing a strong argument for nativist models of human language, may be encompassed within the human-specific orientation and mastery of complex embedded structures, of which language represents one realization. Non-social language learning could thus represent the extension of available linguistic, and non-linguistic material processed by human genetic constraints, allowing language acquisition. This deviation from typical developmental language acquisition may ultimately allow access to language, sometimes in its most elaborate forms, and also explains the possibility of the absence of its development when applied to primarily non-linguistic structured material. However, such enlargement of material-specificity does not cast doubts about its human nature. Regardless of the adaptive success or failure of nonsocial language learning, it is up to science, legal policies, and ethical principles to strive to maintain autism as a human potentiality to further foster our vision of a plural society.
\end{abstract}

Keywords: Language; Autism; Development; Perception; Veridical mapping; Autistic interests; Deep Phenotypes; Clusters /Subtypes; Neurodevelopment 


\section{THE NATURE AND LEVEL OF DIFFERENCES AMONG HUMANKIND IN LANGUAGE ABILITY.}

The alteration of two central human abilities in autism, namely socialization and language, leads to the immense risk of picturing autistic people as nonhuman ${ }^{1}$ or super-human ${ }^{2}$. Autism and typical development can provide information about each other [1]. We consider autism as another form of intelligence, extending, for better or worse, the realization of initial human possibilities. Atypical learning and processing of complex information in autism informs us on the level of abstraction or plasticity of what makes us human in terms of language. It is therefore the complexity (e.g., multi-level isomorphisms or 'embedded structures') of the operations and, in particular, the different realizations of the innate potentiality of language that define this specificity of humans, and not the specific realization, intact or not, of this capacity. The normocentric constructs forged for non-autistic people (e.g. universal grammar, language acquisition device) do not apply to autistic people, without their alteration [2]. Alternatively, the alteration of a function (e.g. language learning) in autistics is not straightforwardly equated with its deficit but rather the adaptation of the human brain to the possible realization of a function by an alternative path. We endorse the limitations of the constructionist model to account for the figures of language learning in prototypical autistic people [3] and propose a new perspective on how autism could enlighten our understanding of language acquisition and development. This article argues that the learning of language by autistic people and its chronology, communicational peculiarities, relationship with other cognitive systems, and extremes of performance or challenges, show how a genetically determined human function, language learning, has led to atypical achievements, while remaining achievements of the same human function that are more abstract and for which the material-specificity is less determined by genetic constraints.

\section{AUTISTIC LEARNING OF COMPLEX STRUCTURES: THE VERIDICAL MAPPING MODEL AS A STRUCTURE ACQUISITION DEVICE.}

\subsection{FROM THE SUPERIOR ROLE OF PERCEPTION IN AUTISM TO THE MASTERY OF GENERATIVE STRUCTURES.}

The ENHANCED PERCEPTUAL FUNCTIONING model (EPF; Mottron et al. [4]) proposes that perception in autism demonstrates superior performance, a greater role, and more autonomy than that observed in the general population. This model is used as an explanatory framework for multiple behavioral, cognitive, and brain imaging variants related to perception and its interaction with the other cognitive functions that characterize autism. In addition to low-level perceptual over-functioning, such as pitch discrimination [5], superiority in pattern detection and manipulation has been demonstrated over the last two decades. Two complementary models have been developed. The TRIGGER-THRESHOLD-TARGET model (TTT) covers the neurobiological mechanisms responsible for EPF, as well as the heterogeneity of language development observed in individuals with the same genetic predisposition for autism [6]. The VERIDICAL MAPPING model (VM) covers the structural homologies shared by informational material involved in autistic savant abilities, either simple (e.g. absolute pitch) or complex (e.g. calendar calculation). It proposes a mechanism for the developmental and creative extension of autistic special abilities

\footnotetext{
${ }^{1}$ Tomasello et al. 2005 'Children with autism, who do not understand or interact with other persons in the species-typical manner'

${ }^{2}$ See Schovanec, J. 2012 'Je suis à l'Est!', Place des éditeurs, 178 p., for a critic
} 
that involve language, such as calendar calculation, and those which are essentially nonverbal, such as three-dimensional drawing, whereas the original EPF model was centered on perception [7].

\subsection{VERIDICAL MAPPING AND AUTISTIC "SPECIAL ABILITIES".}

The first principle of the veridical mapping model states that autistic preschoolers spontaneously detect and orient themselves preferentially towards complex structures that exhibit a higher density of isomorphisms than those for which these properties are absent or less rich. This would explain both autistic children's transient preference for written over oral language and their preference for non-communicative learning of language through highly redundant, computerized presentations. According to this hypothesis, it is the multi-scale, recursive nature of information to which they are exposed that makes it of interest and triggers the implicit learning of their rules and regularities.

A second principle of the VM model is that the autistic brain tends to map isomorphic structures presented in different perceptual modalities onto each other. In the same way that an information format maximizing redundancy triggers an orientation and implicit learning, the structural similarity between two layers of perceptual information, or 'between code isomorphisms', triggers stable, intermodal connectivity between two perceptual expertise regions. The two VM principles may act concurrently, as the choice of ordered series implies an initial grasp of a structure common to elements with a familial resemblance, before their mapping with another homologous element of another ordered sequence [8].

Three manifestations of language-perception coupling are indeed observed with atypical frequency in autism: absolute pitch, synesthesia, and hyperlexia [9]. They all have in common the fact that they are composed of small, perceptually segmented units that present a familial resemblance. This information (pitch scales, colours, numbers and letters) is presented to the child in highly redundant chains, therefore presenting embedded isomorphisms. Written symbols and pitches are a family of forms that share a configurational resemblance and a high level of within and between code recurrence. They form larger redundant units at a higher level of organisation, such as words or musical sentences, that share a roughly similar syntactic structure. At a higher level of organisation, absolute pitch, synesthesia, and early knowledge of letters and numbers involve the stabilisation of coupling between homologous elements belonging to ordered series of auditory and visual information [8]. They all link a language unit with a perceptually defined unit (respectively, the name of a note with the note, the name of a letter with a color or another sensation, the name of a letter with a grapheme).

The neuronal stabilization of these intermodal couplings, linking together the homologous elements of two isomorphic structures, forms the unit from which future autistic 'special abilities' are built: certain autistic musicians have perfect pitch, certain calendar calculators presented with initial hyperlexia, and synesthesia is common to them. An autistic special ability can be simple and have a strong perceptive component. This is true for the three examples given above: producing an element when presented with another coupled item, such as a note and its name for absolute pitch, a letter and a particular color or sensation for synesthesia and pronounced words and written code for hyperlexia.

However, savants also generate new sequences using these units, showing a creative mastery of the laws that compose them, which is not limited to the memorization of the sequences. A striking example is calendar calculation, in which a person who has shown early detection of numbers and letters spontaneously turns to calendars (e.g. Mottron et al. [10]). From 
exposure to only a limited number of calendars, they implicitly understand the laws that govern them. They can then determine the day of the week corresponding to a given date without using an explicit algorithm. Access to this information is bidirectional: the person can give a list of the years in which March begins on a Friday as quickly as they can give the day of the week of July 31,1914 . This 'special ability' appears to function through the mapping of isomorphic structures, such as for special computational abilities, between base 10 and base 60 calculations or between calendar and tonal structure [11]. As discussed in the following, the structural similarity between autistic special abilities and the way autistic people master language may be reciprocally informative.

\section{THE DEVELOPMENTAL SEQUENCE OF LANGUAGE ACQUISITION IN AUTISM.}

\subsection{THE APPARENT HETEROGENEITY OF THE LANGUAGE PHENOTYPE IN AUTISM.}

Language in autism is atypical in many ways - the path and mode of learning, semantics, intonation, discursive thematic analysis, and pragmatics. These were considered to be diagnostic criteria in the early years of the description of autism in school-age children. Moreover, the reduction in the intention to communicate, and most often the very ability to communicate, is intrinsic to the current definition of autism.

However, do these atypical characteristics lessen the aptitude of autistic people to master the mechanics of language? Several observations in the half-century following the discovery of this condition resulted in the dissociation of language ability and autistic communication behaviors. The same people who presented marked and prototypical clinical profiles at preschool age, who were not or minimally verbal, could speak in adulthood. Therefore, that which was deficient or atypical in the autistics' use of language did not necessarily concern language itself. This finding was reinforced by the integration into autism of individuals described by Asperger as those who master complex language from childhood, whereas as adults they exhibited socialization skills and types of interests similar to those described by Kanner. Finally, even for those who attain a certain level of oral communicative language, it can be affected by multiple deficits, which appear to escape systematization.

How then can the same condition be associated with such wide variations in the acquisition, form, and use of language, from silence to exceptional mastery? The operative conclusion to this question in the current diagnostic criteria of autism is that the level of language does not contribute to the identification of autism, but that its impairment or its integrity modify the presentation and adaptive capacity of autistic people. This movement is part of a resignation that autism is heterogeneous, which for us amounts to giving up on understanding what structures its various presentations.

There are three orthogonal variables that structure the autistic language phenotype. First, people receiving an autism diagnosis belong to a bimodal distribution, contrasting those with a speech onset delay (SOD) or an early regression/loss of language (or marked atypicalities in a small proportion of them), who are diagnosed early and correspond to the first prototypical description of autism, and those without SOD, broadly mapping the former category of Asperger syndrome and diagnosed around the end of their preschool years or later (approximately 20\% of the overall prevalence according to Mattila and colleagues [12], but expanding based on current criteria). A third category contains autistic people with a nonverbal intellectual disability, frequently accompanied by identified neurogenetic syndromes, which combine the language limitation associated with intellectual deficiency and an autistic language acquisition trajectory 
(approximately 10-15\% of the overall prevalence; Tammimies et al. [13]). We will focus on the first group, prototypical autism, because it represents a large majority of autistic people, combining fast and reliable identification with the most clearly individualised language phenotype.

\subsection{PRe-CliniCAL PHASE: AtTENTIONAL DIFFERENCES PRECEDING RECOGNITION OF THE SYNDROME.}

Autism in its prototypical form is usually detected by parents around the middle of the second year of life $[14,15]$ through a set of mainly socio-communicative signs (decreased response to name, social synchrony, oriented smiling, initiative and response to joint attention, imitation, and eye contact) and language signs (absence of language development or loss of the few words already acquired by the child.

Before autism is visible to a non-expert observer, low- and high-risk groups are differentiated by the nature of their attention towards social and non-social targets. This has been highlighted by prospective longitudinal studies of siblings of children already diagnosed with autism, one fifth of whom will be diagnosed later. Perceptual signs start to diverge from typical development at nine months of age, on average [16], whereas social signs start to diverge at 12 months [17]. From the age of 13 months, alterations in these two domains predict, additively but independently and sometimes in isolation, the subsequent occurrence of a prototypical autistic presentation [18]. Both precede the objectivation of language delay [19].

A meta-analysis of the non-social signs preceding the diagnosis [20] revealed that children sharing the same genetic predisposition, regardless of their future diagnosis, visually fix on objects for longer durations [21, 22] at the end of the first year of life. At 12 months, most children who will later be diagnosed with autism present atypical visual exploration [23]. Prolonged target fixation can be seen either as a deficit of disengagement [24] or, on the contrary, as the effect of superiority in the detection of targets and visual search, particularly of letters, as attested by several convergent studies [25-28]. The latter is consistent with one third to one half of diagnosed autistic children exhibiting enhanced nonverbal abilities for their chronological age [29]. The manifestations of auditory hypersensitivity (covering ears with their hands when exposed to physical noises or human voice) are maximal during the non or minimally verbal period [30]. Atypical socio-communicative behaviors and interests are observed before the emergence of formal language and even before its atypical development is noticed.

\subsection{ATYPICAL LANGUAGE PROGRESSION.}

In the early years, the attention of autistic children is directed towards interests that are mostly non-social, which is coherent with the observed plateau of several years without evident progress of the development of social, language, adaptive, and imaginative neurotypical skills [31-33]. This is emphasized in the case of oral language when the apparent plateau follows a regression - the loss of previously acquired words after apparent typical development. In these children, the first words are reported by parents to occur at the same time as those of typical children, but the time period between the first words and two-word sentences is at least doubled [34]. These autistic children may remain silent for several years or only utter unrecognizable vocalizations.

The language plateau is not always characterized by complete silence: the absence of communicative language (requests or instances of interactive speech, the use of pragmatic terms) 
can coexist with 'labels' identifying 'natural kinds' [35]. The child thus names aloud the shapes he/she encounters, most often those belonging to an ordered series that he/she is interested in (letters, numbers, colors, geometric shapes, animals) [36]. When these shapes are letters, the situation has been individualized as hyperlexia. In its most extreme forms, the child reads fluently but does not speak (see for example: [37-40]; such a large discrepancy between reading skills and oral language level is found in 29 of the 82 published cases of hyperlexia [41]. Access to and the understanding of language codes in such cases relies more on non-communicative forms of language than in neurotypical children. This is consistent with the results of preliminary studies suggesting that half of prototypical autistic children with access to screens present an interest in and knowledge of letters and numbers during their third year of life, significantly ahead of general population norms [U.S. Department of 42]. For a large portion, letters are learned in a language other than that spoken at home.

The progression of expressive language is marked by a succession of atypical language features, modulated by chronological age and IQ: immediate echolalia in the presence of a frequently age-appropriate phonology [43], then delayed echolalia, then pronoun reversal, then stereotyped language [44]. Immediate echolalia is more characteristic of autism when it consists in the verbatim repetition of exchanges between people that are not addressed to the child, now mostly extracted from television/YouTube programs. It differs from the echolalia of sentences addressed to the child observed during typical language acquisition and predominant in nonautistic language disorders. Immediate echolalia testifies to phonological (prosodically contrastive echolalia) and a fortiori syntactic restructuring [45], which demonstrates its partially communicative and semantic nature or intention. Delayed echolalia involves sentences that are presented several times in the same way in the environment at some distance from their occurrence: cartoons, advertisements, or parental instructions. We can sometimes grasp, on the fly, the transformation of stereotyped language into syntactically normal language in the form of mitigated echolalia [46], that is the lessening of deferred echolalia by substitution of one of the original terms by a more adequate term for the current utterance situation. Better understanding is associated with increased mitigation [47]. Stereotypical language is functional, but keeps traces (word order, adult language, accents) of its origin, and is heard identically on multiple occasions. In an extension of this phenomenon, in pronoun reversal (when the child asks for a drink by saying 'you want water'), the child makes a request maintaining the personal pronoun used by others to address him/her. Such pronominal inversion represents the last form of delayed echolalia before the mastery of 'normal' language. However, it retains a certain level of rigidity, hyper-grammaticality, and formalism [48-50], which retain their diagnostic value in adulthood.

All of these peculiarities are most prevalent around the age of 4 to 6 years, at the resumption of language at the end of the plateau and disappear for the most part when language normalizes [51]. The plateau can last until the age of 8 [52], 9 [53], or 11 [54]. The late emergence of language is also well documented in autism, as shown by Picket and colleagues [55], who identified 167 autistic children who acquired language after five years of age in a conservative review. Anecdotal cases of language recovery in adulthood have also been reported [56]. The slope of acquisition, once language progression has restarted, is generally steep [53, 57]. Kanner [58] noticed that nonverbal autistic children surprised their parents in emergency situations when they pronounced grammatically correct sentences, suggesting that they had accumulated a large amount of language information before their first use of speech. Two studies $[59,60]$ reported the sudden emergence of fully formed speech after the apparition of reading 
skills in several subjects. The extent of oral language recovery has been associated with the level of nonverbal IQ [34, 53, 57].

Meta-analyses on the effect of interventions on language recovery, whether it is before five years of age or later, show that they have only a minimal influence on the language development of these children [61-63]. Language, when it occurs, is essentially self-taught [3], and autonomous access to written or web-based information could play a major role [41, 64, 65]. Although nonverbal IQ remains the major predictor of ultimate language access, it does not guarantee it [66]. A quarter [67, 68] to a half [69] of autistic children under the age of 10 are considered to be mute or minimally verbal. The notion of nonverbal autism must indeed be viewed critically, as its definition is uncertain [70].

In summary, the maturation of oral language in prototypical autistic children follows a bayonet-shaped sequence: an almost normal start, an atypical imbalance of interests and attention for auditory and verbal stimuli, followed by a nonverbal or minimally verbal plateau, and atypical, rapid resumption, resulting most often in syntactically correct language after six years of age. The development of language in autism does not follow a typical timeline, but the extension of its development is central to the condition and is independent of the level that will be reached. In a substantial proportion of cases, this sequence is coupled with an early interest in written code, with decoding skills superior to comprehension in the hyperlexic period. In most cases, it predicts a catching up in reading comprehension after five years of age. The nature of the oral utterances or reading prerequisites that the child demonstrates during this sequence suggests that oral and written language are not primarily learned in a communicative way in autism. We will try to explain this in the next section.

\subsection{SPECIAL SKILLS AND LANGUAGE FOLLOW SIMILAR DEVELOPMENT PATHS IN AUTISM.}

There are deep similarities between the way people with autism develop a special ability and their sequence of language acquisition (see Table 1). Most intense interests and autistic special abilities contain a language element [71]. In autism, both language and autistic special abilities are self-taught and implicit, and they favour large scale isomorphic units, as shown by the delayed echolalia of sentences presented in a fixed format. Both involve language in the visual modality (letter recognition) earlier or at a higher level than in typical children. Both provide evidence that language can develop without the evidence of social reinforcement [3] and are associated with a delay in oral language in a large fraction of the autistic population.

We propose that exposure to language itself is the element that 'triggers' both the development of special abilities and of language in autism. However, such language needs to be presented in a more isomorphic manner and with a higher level of structural recurrence (written language, calendars, YouTube nursery rhymes, etc.) than the oral language to which typical children are exposed in their environment. More importantly, the detection-coupling-syntax developmental scheme may be the same for language and special abilities. Both cases include the following steps: a) detection of structural laws in the chosen material comprised of identical units constituting larger structures, b) mapping of units from one modality to their counterpart in another modality, c) stabilization of the coupling between the homologous elements, and d) generative mastery of a code with several embedded levels, allowing the production of a new well-formed utterance.

In short, the heterogeneity of the fields to which scholarly capacities are applied in autism, as well as their structural similarity, allow abstraction of the principles at stake beyond 
the modality of the domain of information involved. Language learning and special abilities in autism may arise from the same mechanism, provided that the class of objects to which they apply is widened. However, this difference does not alter the fundamental principles ruling them, nor, consequently, the fundamental humanity of this process. These principles are also, as we shall see, those that govern the language learning of typical children. 
TABLE 1. Common unfolding of savant abilities and its relationship with the non-autistic acquisition of oral language.

\begin{tabular}{|c|c|c|c|c|c|c|c|c|c|c|}
\hline Competence & $\begin{array}{l}\text { Triggering } \\
\text { exposure }\end{array}$ & $\begin{array}{c}\text { Unity of } \\
\text { information }\end{array}$ & Mapping & Generativity & Recursivity & $\begin{array}{c}\text { Associated } \\
\text { behaviors }\end{array}$ & $\begin{array}{c}\text { Chained } \\
\text { information }\end{array}$ & $\begin{array}{c}\text { Imprinting } \\
\text { effect }\end{array}$ & $\begin{array}{l}\text { Embedded } \\
\text { structure }\end{array}$ & Generativty \\
\hline $\begin{array}{l}\text { Non-autistic } \\
\text { speech }\end{array}$ & $\begin{array}{l}\text { Oral mother } \\
\text { tongue }\end{array}$ & Lexicon & $\begin{array}{l}\text { Word- } \\
\text { object, } \\
\text { referential } \\
\text { use of } \\
\text { language }\end{array}$ & $\begin{array}{l}\text { Producing new } \\
\text { well-formed } \\
\text { sentences }\end{array}$ & $\begin{array}{l}\text { Embedded } \\
\text { sentences }\end{array}$ & $\begin{array}{l}\text { Imitation, } \\
\text { joint } \\
\text { reference }\end{array}$ & $\begin{array}{l}\text { Syntactization } \\
\text { of two-word } \\
\text { sentences }\end{array}$ & $\begin{array}{l}\text { Irreversibility of } \\
\text { Mother tongue }\end{array}$ & Syntax & $\begin{array}{l}\text { Producing and } \\
\text { understanding } \\
\text { new sentences }\end{array}$ \\
\hline $\begin{array}{l}\text { Autistic } \\
\text { hyperlexia }\end{array}$ & $\begin{array}{l}\text { Combined } \\
\text { written and } \\
\text { oral signs }\end{array}$ & $\begin{array}{l}\text { Letters and } \\
\text { numbers }\end{array}$ & $\begin{array}{l}\text { Isomorphic } \\
\text { graphic- } \\
\text { phonic } \\
\text { structure }\end{array}$ & $\begin{array}{c}\text { Reading } \\
\text { unknown words }\end{array}$ & $\begin{array}{l}\text { Word-letter } \\
\text { embedded in } \\
\text { sentence } \\
\text { structure }\end{array}$ & $\begin{array}{l}\text { Orientation } \\
\text { toward } \\
\text { written code }\end{array}$ & $\begin{array}{l}\text { Decoding } \\
\text { ability }\end{array}$ & $\begin{array}{l}\text { Fixation of } \\
\text { domain of } \\
\text { interest }\end{array}$ & Written code & $\begin{array}{l}\text { Reading } \\
\text { ability with } \\
\text { semantic } \\
\text { access }\end{array}$ \\
\hline $\begin{array}{l}\text { Verbal savant } \\
\text { ability (e.g. } \\
\text { calendrical } \\
\text { calculation) }\end{array}$ & Calendars & Dates & $\begin{array}{l}\text { Isomorphic } \\
\text { calendar } \\
\text { structure }\end{array}$ & $\begin{array}{l}\text { Producing non- } \\
\text { memorized } \\
\text { dates }\end{array}$ & $\begin{array}{l}\text { Month-day } \\
\text { dates } \\
\text { embedded in } \\
\text { yearly } \\
\text { structure }\end{array}$ & $\begin{array}{c}\text { Intense } \\
\text { interests for } \\
\text { dates }\end{array}$ & $\begin{array}{l}\text { Cracking } \\
\text { calendrical } \\
\text { structure }\end{array}$ & $\begin{array}{l}\text { Fixation of } \\
\text { domain of } \\
\text { interest }\end{array}$ & $\begin{array}{l}\text { Calendrical } \\
\text { structure }\end{array}$ & $\begin{array}{l}\text { Production of } \\
\text { unexposed } \\
\text { calendar } \\
\text { information }\end{array}$ \\
\hline $\begin{array}{l}\text { Visuo-spatial } \\
\text { savant ability } \\
\text { (e.g. 3-D } \\
\text { drawing) }\end{array}$ & 3-D objects & Geons & $\begin{array}{l}\text { Isomorphic } \\
\text { visual- } \\
\text { graphic } \\
\text { structures } \\
\text { Lining up of } \\
\text { objects }\end{array}$ & $\begin{array}{l}\text { Producing } \\
\text { graphic 3-D } \\
\text { transformations }\end{array}$ & $\begin{array}{l}\text { Micro 3-D } \\
\text { scale } \\
\text { embedded in } \\
\text { 3-D macro } \\
\text { scale }\end{array}$ & $\begin{array}{l}\text { Lining up, } \\
\quad \text { visual } \\
\text { inspections }\end{array}$ & $\begin{array}{l}\text { Sequences of } \\
\text { physical } \\
\text { transformations }\end{array}$ & $\begin{array}{c}\text { Fixation of } \\
\text { domain of } \\
\text { interest }\end{array}$ & $\begin{array}{l}\text { Mechanical } \\
\text { structure }\end{array}$ & $\begin{array}{c}\text { Complex } \\
\text { physical } \\
\text { productions }\end{array}$ \\
\hline $\begin{array}{l}\text { Musical savant } \\
\text { ability }\end{array}$ & $\begin{array}{l}\text { Musical } \\
\text { pieces }\end{array}$ & Pitches & $\begin{array}{l}\text { Isomorphic } \\
\text { musical } \\
\text { structures }\end{array}$ & $\begin{array}{l}\text { Composing new } \\
\text { musical } \\
\text { sentences }\end{array}$ & $\begin{array}{l}\text { Pitch/ musical } \\
\text { sentence } \\
\text { embedded in } \\
\text { musical piece }\end{array}$ & & & & & \\
\hline
\end{tabular}




\subsection{COMPARATIVE APPROACH BETWEEN AUTISTIC LANGUAGE AND CHOMSKYAN NATIVISM.}

Although their nature is still a subject of debate, there are genetic constraints to the orientation towards oral language and its acquisition. These include the 'innate biases and strategies that place constraints on perception and learning' which 'set the parameters for a particular pattern from among those innately provided' [72]. In Chomskyan nativism [73], the faculty of language - narrow sense (FLN) includes the core computational mechanisms of recursion that allow syntax generativity and its mapping to perceptual and motor interfaces. The acquisition of language is dependent on an ability to recognize language, detect a recursive structure in it, and adapt to one's mother tongue. The high level of abstraction of syntactic universals is revealed in a comparative approach, allowing common and different aspects to emerge between the acquisition of various syntactic structures by humans.

Just as the comparison of human languages defines the level of abstraction of universals of acquisition and structure specific to human language, comparison of the various special autistic abilities informs us about their development and common neurocognitive mechanisms. We support Kissine's [3] statement that autism can help us determine the constraints of the level of abstraction needed for the extraction of language structure and language acquisition in humans. This requires, in addition to a simple comparative approach between different realizations of the same ability, a meta-comparison between the plurality of typical language achievements and the plurality of special autistic abilities, which may rely on the same core aptitudes or mechanisms. The meta comparison between autistic and non-autistic deployment of special abilities and language potentiality, respectively, reveal how both manifest a common, human property of language generativity and the mastery of recursive structures. We are therefore at odds with the dehumanizing conclusions of Pinker $^{3}(2002: 62)$ or Tomasello ${ }^{4}$ (2005:689) for whom the triangular comparison of typical humans - apes - autism results in a rejection of autism and its being outside humanity.

The emergence of autistic special abilities follows exposure to structured material that shares commonalities with language. The formal properties and our improved understanding of the materials on which autistic intense interests are directed and which permit the development of special abilities reveal common mechanisms and constraints with language. For example, each of the two components of multimodal units, such as perfect pitch, synesthesia, letter denomination, or calendar calculation, all belong to a) finite families of b) highly similar shapes each time they occur, c) presented spatially or sequentially in real terms, and d) structured by complex but recurring constraints (or within/between code isomorphisms). Such invariance

\footnotetext{
3 'Together with robots and chimpanzees, people with autism remind us that cultural learning is possible only because neurologically normal people have innate equipment to accomplish it'. Pinker 2002, P.62

4 ' $n e$ ither apes nor children with autism have - at least not to the same extent as typically developing human children - the motivation or capacity to share things psychologically with others. This means that they both have very limited skills for creating things culturally with other persons'. Tomasello 2005, P.689
} 
suggests that all of these characteristics, albeit quite minimal, are sufficient to trigger an interest or orientation and be the subject of subsequent mastery, including language generativity.

The 'bayonet-shaped' sequence of language acquisition in prototypical autism is comprised of two phases, the plateau, which is generally seen as a language 'delay', followed by late language progression. As discussed earlier, late progression in approximately $7 \%$ of cases actually represents a quick catch up to the expected language levels for their age [53, 57]. This late catch-up raises many questions about the fact that it occurs in children in whom their initial prelinguistic skills may appear to be deficient due to the atypicality of their social behavior. The veridical mapping framework allows us to suppose that the abilities required for language acquisition, such as the mastery of recursive structures, are initially used and developed in other spheres related to autistic children's interests and will subsequently be useful or reused for linguistic decoding. Language progression would then be delayed, and language decoding would therefore be less dependent on social cues and rely more on the structure of the exposed material [64]. It should therefore not be surprising that the acquisition of language is atypical in its timeline, peculiarities, and rigidities.

\section{4. 'MATERIAL SPECIFICITY' AND HUMAN SPECIFICITY.}

\subsection{CORTICAL REALLOCATION AND IDIOSYNCRASY IN AUTISM IN LANGUAGE-RELATED TASKS.}

Language in autism can be understood from the viewpoint of the heterogeneity of autistic language phenotypes - from impaired to exceptional - and the steps of its development [7]. Brain activity associated with oral language is at first abnormally low, and then atypically localised. Children with a genetic predisposition to autism display a hyper-connected auditory-motor association cortex at nine months, but low specialisation for voice [74]. Importantly, around the age of language acquisition, autistic people show enhanced auditory-visual connectivity within the language regions and between them and the visual cortex, consistent with the auditivo-visual advances observed in multimodal coupling [75]. These alterations, together with a reduction in the lateralisation of activation when exposed to oral speech, are among those that predict an autism diagnosis at 24 months [76]. This pattern can still be observed in adulthood [77, 78]. This differentiates autistic adults with and without an initial speech onset delay, who present with considerable differences in cortical allocation [79, 80]. The variability of cerebral allocation in areas of perceptual expertise can therefore be observed both at the individual level and at that of the autistic group considered as a whole. When exposed to speech-like material, autistic adults who had a SOD show overactivation of the Heschl gyrus and the area responsible for the perceptual part of language processing. Alternatively, autistic individuals who did not have a language delay show activation of a large area that includes the brain cortex that is activated in neurotypicals when processing language linguistically, and even extends to motor cortices [80].

In the visual modality, there is greater variability in brain expertise regions. The relative weighting of the activation $[81,82]$ and connectivity $[83,84]$ of perceptual vs. language networks in linguistic tasks deviates towards domain-specific visual expertise. This has been verified in language tasks [85], as well as reasoning tasks [86], for which they are advantageously associated. On the other hand, the localization of activation observed during information processing that leads to circumscribed localization in the typical person is both different from that of typical people when averaged, and more different between autistic individuals than between typical people [87]. Overall, this indicates widening of the genetic 
constraints of neural and functional allocation of expertise regions, particularly those devoted to language processing.

\subsection{AUTISM INVOLVES THE WIDENING OF A GENETIC CONSTRAINT TOWARD LANGUAGE MATERIAL-SPECIFICITY.}

The variations of brain activity observed between autistic and non-autistic people during linguistic tasks predominate in regions that developed the latest in evolution $[88,89]$ and that maintain cross-modal plasticity during early deprivation of perceptual input [6]. On the other hand, the widening of the 'material-specific' constraints observed in autism during oral language acquisition suggests an alteration of the mechanism responsible for the orientation toward, and selection of, the material producing the first linguistic units in neurotypicals. Therefore, we understand development concerning language (and complex information in general) in autistic people as the enlargement of the typical language-specific coupling between brain specialisation and language. We propose that the inborn linguistic parsing mechanisms orient preferentially toward any materials with 'embedded structures'- what we have called a high density of isomorphisms- instead of primarily oral communicative language as it does in typical people. This extension would apply to any material possessing these properties, possibly to the detriment of oral language. This model is suggested by a) the atypical demonstration of attention that precedes the developmental break or language regression and plateau, b) the abstract similitude of the autistic and non-autistic sequence of integration of embedded structures, and c) the enhanced variability of functional and anatomical allocation of the regions involved in the development and use of language in autistic people.

Variability in dominant material-specific constraints or atypical coupling between a specific material and a brain function is the rule and not the exception in phylogenesis, as in individual development. They are found at the individual level following the absence of auditory or visual input (e.g. cross-modal plasticity in early visual impairment; Collignon and colleagues [90]), mid-term at the population scale (recycling of the VWFA; Dehaene-Lambertz and colleagues [91]), and long-term at the evolutionary level. They have been conceptualized, with certain differences, as neural reuse [92] or exaptation [93] and were involved in the evolution of human language. Their latest manifestation is the existence of and neural allocation for written code. When the coupling between information processing units and information present in the living environment opens up, as in reading, this is 'cultural reuse' [94].

The material specificity for an area of intense interest is determined by exposure to certain material and subsequent to prolonged inspection behavior. Just as there is a critical period for learning the mother tongue for a typical person in the early preschool years, the material of which the structures have caused reorientation of the autistic child towards a non-social universe causes a 'freeze' around the material, within a certain modality, constituting the restriction of the autistic domain of interest. We separate the human specificity in dealing with complex structures - the potential material specificity for language - from the relative domain-specificity of these mechanisms once they have come into place for a particular individual speaking a particular language. We distinguish the material-specificity (the linguistic nature or not of what triggers the processes, of which typical language learning would be a special case) from the domainspecificity inherent to the processing of complex information once such learning has taken place. The specialization of a language for a neurotypical group and specialization of an interest for an autistic person, in particular, would therefore be phenomena of the same nature (but see Anderson and Penner-Wilger [95]). 


\subsection{MAINTAINING AUTISM IN HUMANITY.}

The enlargement of the scope of information preferentially processed during infancy in autism does not imply a non-human or super-human autistic nature. Privileging written language, calendars, or visual structures suggests an orientation towards materials that maximize the density of isomorphisms such as those found in human oral language. Moreover, most autistic people usually end up speaking, and a certain number of them speak earlier and better that the typical population. Beyond the strong similarity between typical language acquisition and autistic special abilities, the level and nature of autistic intelligence confirms that autism belongs to what is most human in humans. A quarter of the siblings of autistic children, who therefore share the same predisposition to autism as their autistic relative, are two standard deviations ahead of the non-autistic population at the same age. Forty percent of them have a higher level of nonverbal intelligence than the general population [29]. A previous study showed that when a group of autistic adults were matched to typical adults for global IQ, the autistic group showed much higher intelligence measured by nonverbal reasoning than by a verbal intelligence measure [66] and were $40 \%$ faster than a comparison group in performing these tasks [86]. The common low-effect genetic variants associated with prototypical autism are also those associated with intelligence in typical people [96, 97]. The level of 'severity', as well as the verbal or nonverbal status of an autistic person, is independent of this genetic predisposition to autism [98, 99]. Prototypical autism is thus another combination of verbal and nonverbal intelligence and not a disease of intelligence.

Access to language in autism, with its divergences and convergences with predominant paths, results from a deep identity with the access to language that constitutes humanity. Autism consists of the opening of the potentialities of detection, learning, and manipulation of complex human information to families of non-socially determined forms and structures. It has been known since K. Lorenz that the relative absence of fixed material-specific instinctual sequences goes hand in hand with intelligence: crows are smarter than cranes. The extension of the material processed by a genetically transmitted function and its cultural stabilization is undoubtedly a source of human progress - as long as, in the case of autistic people, this diversity is welcome. Neural reuse (or recycling/exaptation) is the norm and not the exception in evolution [93, 95]. These apparent inflections in adaptation are involved in what makes humans what they are, specifically in terms of the invention and use of language, and within language, the ability to read. Emphasizing the reduced dependence of autistic people on social triggers in language development, the major argument of Pinker and Tomasello for their dehumanizing position toward autism, considers the most superior aspect of humans their most animal part: their gregariousness.

It is necessary to alter the conception of autism as a mistake in favor of an abstraction of the humanity of man. Such accomplishments occur by an original path, which may explain both the success and challenges of autism. The decisions taken by the majority of humans through scientific models of autistic differences (variants in prototypical autism vs. deleterious mutation in syndromic autism), the anthropological status of these differences (contributory to humanity or a disease to be cured), the delineation between autism and non-autism (categorical or dimensional), and their ethical and societal consequences (cure or integrate) are intricate and influence each other. Kicking autism out of humanity appears to be a recurrent temptation, sometimes based on short-sighted views, such as using mouse-based behaviorist intervention programs, and sometimes on sophisticated phylogenetic considerations, such as conceptually 
depriving them of what differentiates humans from apes. In both cases, we see this as ethically outdated, scientifically wrong, and heuristically sterile.

\section{FUNDING}

This research was funded by Marcel \& Rolande Gosselin Research Chair in autism at the University of Montreal.

\section{ACKNOWLEDGMENTS}

The authors would like to thank Dr Mikhail Kissine for his comments on a previous version of this manuscript.

\section{Author Contributions}

Conceptualization, L.M.; Writing - Original Draft Preparation, L.M., A.O. and D.G.; Writing Review \& Editing, L.M., A.O. and D.G.; Supervision, L.M.; Funding Acquisition, L.M.

\section{CONFLICTS OF INTEREST}

The authors declare no conflict of interest.

The sponsors had no role in the design, execution, interpretation, or writing of the study. 


\section{REFERENCES}

1. Burack, J. A., G. larocci, D. Bowler, and L. Mottron. "Benefits and Pitfalls in the Merging of Disciplines: The Example of Developmental Psychopathology and the Study of Persons with Autism." Dev Psychopathol 14, no. 2 (2002): 225-37.

2. Mottron, L., M. Dawson, I. Soulières, and M. Dawson. "A Different Memory: Are Distinctions Drawn from the Study of Nonautistic Memory Appropriate to Describe Memory in Autism?" In Memory in Autism, edited by J. Boucher and D. Bowler, 311-29: Cambridge University Press, 2008.

3. Kissine, M. "Perspectives: Autism, Constructionism and Nativism." Language (2020).

4. Mottron, L., M. Dawson, I. Soulieres, B. Hubert, and J. Burack. "Enhanced Perceptual Functioning in Autism: An Update, and Eight Principles of Autistic Perception." J Autism Dev Disord 36, no. 1 (2006): 27-43.

5. Mayer, J. L., I. Hannent, and P. F. Heaton. "Mapping the Developmental Trajectory and Correlates of Enhanced Pitch Perception on Speech Processing in Adults with Asd." J Autism Dev Disord 46, no. 5 (2016): 1562-73.

6. Mottron, L., S. Belleville, G. A. Rouleau, and O. Collignon. "Linking Neocortical, Cognitive, and Genetic Variability in Autism with Alterations of Brain Plasticity: The Trigger-Threshold-Target Model." Neurosci Biobehav Rev 47C (2014): 735-52.

7. Mottron, L., L. Bouvet, A. Bonnel, F. Samson, J. A. Burack, M. Dawson, and P. Heaton. "Veridical Mapping in the Development of Exceptional Autistic Abilities." Neurosci Biobehav Rev 37, no. 2 (2013): 209-28.

8. Pring, L., and B. Hermelin. "Numbers and Letters: Exploring an Autistic Savant's Unpracticed Ability." Neurocase 8, no. 4 (2002): 330-7.

9. Mottron, L., M. Dawson, and I. Soulieres. "Enhanced Perception in Savant Syndrome: Patterns, Structure and Creativity." Philos Trans R Soc Lond B Biol Sci 364, no. 1522 (2009): 1385-91.

10. Mottron, L., K. Lemmens, L. Gagnon, and X. Seron. "Non-Algorithmic Access to Calendar Information in a Calendar Calculator with Autism." J Autism Dev Disord 36, no. 2 (2006): 239-47.

11. Bouvet, L., S. Donnadieu, S. Valdois, C. Caron, M. Dawson, and L. Mottron. "Veridical Mapping in Savant Abilities, Absolute Pitch, and Synesthesia: An Autism Case Study." Front Psychol 5 (2014): 106.

12. Mattila, M. L., M. Kielinen, K. Jussila, S. L. Linna, R. Bloigu, H. Ebeling, and I. Moilanen. "An Epidemiological and Diagnostic Study of Asperger Syndrome According to Four Sets of Diagnostic Criteria." J Am Acad Child Adolesc Psychiatry 46, no. 5 (2007): 636-46.

13. Tammimies, K., C. R. Marshall, S. Walker, G. Kaur, B. Thiruvahindrapuram, A. C. Lionel, R. K. Yuen, M. Uddin, W. Roberts, R. Weksberg, M. Woodbury-Smith, L. Zwaigenbaum, E. Anagnostou, Z. Wang, J. Wei, J. L. Howe, M. J. Gazzellone, L. Lau, W. W. Sung, K. Whitten, C. Vardy, V. Crosbie, B. Tsang, L. D'Abate, W. W. Tong, S. Luscombe, T. Doyle, M. T. Carter, P. Szatmari, S. Stuckless, D. Merico, D. J. Stavropoulos, S. W. Scherer, and B. A. Fernandez. "Molecular Diagnostic Yield of Chromosomal Microarray Analysis and Whole-Exome Sequencing in Children with Autism Spectrum Disorder." JAMA 314, no. 9 (2015): 895-903.

14. Chawarska, K., R. Paul, A. Klin, S. Hannigen, L. E. Dichtel, and F. Volkmar. "Parental Recognition of Developmental Problems in Toddlers with Autism Spectrum Disorders." J Autism Dev Disord 37, no. 1 (2007): 62-72.

15. De Giacomo, A., and E. Fombonne. "Parental Recognition of Developmental Abnormalities in Autism." Eur Child Adolesc Psychiatry 7, no. 3 (1998): 131-6.

16. Sacrey, L. A., L. Zwaigenbaum, S. Bryson, J. Brian, I. M. Smith, W. Roberts, P. Szatmari, C. Roncadin, N. Garon, C. Novak, T. Vaillancourt, T. McCormick, B. MacKinnon, S. Jilderda, and V. 
Armstrong. "Can Parents' Concerns Predict Autism Spectrum Disorder? A Prospective Study of High-Risk Siblings from 6 to 36 Months of Age." J Am Acad Child Adolesc Psychiatry 54, no. 6 (2015): 470-8.

17. Zwaigenbaum, L., S. Bryson, and N. Garon. "Early Identification of Autism Spectrum Disorders." Behav Brain Res 251 (2013): 133-46.

18. Bedford, R., A. Pickles, T. Gliga, M. Elsabbagh, T. Charman, M. H. Johnson, and Basis Team. "Additive Effects of Social and Non-Social Attention During Infancy Relate to Later Autism Spectrum Disorder." Dev Sci 17, no. 4 (2014): 612-20.

19. Wolff, J. J., A. F. Dimian, K. N. Botteron, S. R. Dager, J. T. Elison, A. M. Estes, H. C. Hazlett, R. T. Schultz, L. Zwaigenbaum, J. Piven, and Ibis Network. "A Longitudinal Study of Parent-Reported Sensory Responsiveness in Toddlers at-Risk for Autism." J Child Psychol Psychiatry 60, no. 3 (2019): 314-24.

20. Canu, D., S. Van der Paelt, R. Canal-Bedia, M. Posada, M. Vanvuchelen, and H. Roeyers. "Early Non-Social Behavioural Indicators of Autism Spectrum Disorder (Asd) in Siblings at Elevated Likelihood for Asd: A Systematic Review." Eur Child Adolesc Psychiatry (2020).

21. Zwaigenbaum, L., S. Bryson, T. Rogers, W. Roberts, J. Brian, and P. Szatmari. "Behavioral Manifestations of Autism in the First Year of Life." Int J Dev Neurosci 23, no. 2-3 (2005): 143-52.

22. Elsabbagh, M., J. Fernandes, S. J. Webb, G. Dawson, T. Charman, M. H. Johnson, and Team British Autism Study of Infant Siblings. "Disengagement of Visual Attention in Infancy Is Associated with Emerging Autism in Toddlerhood." Biol Psychiatry 74, no. 3 (2013): 189-94.

23. Ozonoff, S., S. Macari, G. S. Young, S. Goldring, M. Thompson, and S. J. Rogers. "Atypical Object Exploration at 12 Months of Age Is Associated with Autism in a Prospective Sample." Autism 12, no. 5 (2008): 457-72.

24. Elsabbagh, M., A. Volein, K. Holmboe, L. Tucker, G. Csibra, S. Baron-Cohen, P. Bolton, T. Charman, G. Baird, and M. H. Johnson. "Visual Orienting in the Early Broader Autism Phenotype: Disengagement and Facilitation." J Child Psychol Psychiatry 50, no. 5 (2009): 637-42.

25. Cheung, C. H. M., R. Bedford, M. H. Johnson, T. Charman, T. Gliga, and Basis team. "Visual Search Performance in Infants Associates with Later Asd Diagnosis." Dev Cogn Neurosci 29 (2018): 4-10.

26. Gliga, T., R. Bedford, T. Charman, M. H. Johnson, and BASIS Team. "Enhanced Visual Search in Infancy Predicts Emerging Autism Symptoms." Curr Biol 25, no. 13 (2015): 1727-30.

27. Kaldy, Z., I. Giserman, A. S. Carter, and E. Blaser. "The Mechanisms Underlying the Asd Advantage in Visual Search." J Autism Dev Disord 46, no. 5 (2016): 1513-27.

28. Kaldy, Z., C. Kraper, A. S. Carter, and E. Blaser. "Toddlers with Autism Spectrum Disorder Are More Successful at Visual Search Than Typically Developing Toddlers." Dev Sci 14, no. 5 (2011): 980-8.

29. Landa, R. J., A. L. Gross, E. A. Stuart, and M. Bauman. "Latent Class Analysis of Early Developmental Trajectory in Baby Siblings of Children with Autism." J Child Psychol Psychiatry 53, no. 9 (2012): 986-96.

30. Schwartz, S., L. Wang, B. G. Shinn-Cunningham, and H. Tager-Flusberg. "Atypical Perception of Sounds in Minimally and Low Verbal Children and Adolescents with Autism as Revealed by Behavioral and Neural Measures." Autism Res 13, no. 10 (2020): 1718-29.

31. Bussu, G., E. J. H. Jones, T. Charman, M. H. Johnson, J. K. Buitelaar, and Basis Team. "Latent Trajectories of Adaptive Behaviour in Infants at High and Low Familial Risk for Autism Spectrum Disorder." Mol Autism 10 (2019): 13.

32. Landa, R. J., A. L. Gross, E. A. Stuart, and A. Faherty. "Developmental Trajectories in Children with and without Autism Spectrum Disorders: The First 3 Years." Child Dev 84, no. 2 (2013): 42942. 
33. Bruyneel, E., E. Demurie, P. Warreyn, W. Beyers, S. Boterberg, C. Bontinck, N. Dewaele, and H. Roeyers. "Language Growth in Very Young Siblings at Risk for Autism Spectrum Disorder." Int J Lang Commun Disord 54, no. 6 (2019): 940-53.

34. Gagnon, D., A. Zeribi, E. Douard, V. Courchesne, B. Rodriguez-Herreros, G. Huguet, S. Jacquemont, M. A. Loum, and L Mottron. "Bayonet-Shaped Language Development in Autism: A Retrospective Study. Université De Montréal, Ms.", 2020.

35. Perkins, M. R., S. Dobbinson, J. Boucher, S. Bol, and P. Bloom. "Lexical Knowledge and Lexical Use in Autism." J Autism Dev Disord 36, no. 6 (2006): 795-805.

36. Jacques, C., V. Courchesne, A. S. Meilleur, S. Mineau, S. Ferguson, D. Cousineau, A. Labbe, M. Dawson, and L. Mottron. "What Interests Young Autistic Children? An Exploratory Study of Object Exploration and Repetitive Behavior." PLoS One 13, no. 12 (2018): e0209251.

37. Huttenlocher, P.R., and J. Huttenlocher. "A Study of Children with Hyperlexia." Neurology 23 (1973): 1107-16.

38. Craig, H. K., and A. S. Telfer. "Hyperlexia and Autism Spectrum Disorder: A Case Study of Scaffolding Language Growth over Time." Top. Lang. Disord. 25 (2005): 11.

39. Atkin, K., and M. P. Lorch. "Hyperlexia in a 4-Year-Old Boy with Autistic Spectrum Disorder." Journal of Neurolinguistics 19, no. 4 (2006): 253-69.

40. Kasari, C., N. Brady, C. Lord, and H. Tager-Flusberg. "Assessing the Minimally Verbal School-Aged Child with Autism Spectrum Disorder." Autism Res 6, no. 6 (2013): 479-93.

41. Ostrolenk, A., B. Forgeot d'Arc, P. Jelenic, F. Samson, and L. Mottron. "Hyperlexia: Systematic Review, Neurocognitive Modelling, and Outcome." Neurosci Biobehav Rev 79 (2017): 134-49.

42. Education, U.S. Department of. "Typical Language Accomplishments for Children, Birth to Age 6 - Helping Your Child Become a Reader; Https://Www2.Ed.Gov/Parents/Academic/Help/Reader/Part9.Html." 2003.

43. Fay, W. H., and B. V. Butler. "Echolalia, Iq, and the Developmental Dichotomy of Speech and Language Systems." J Speech Hear Res 11, no. 2 (1968): 365-71.

44. Fay, W. H. "Personal Pronouns and the Autistic Child." J Autism Dev Disord 9, no. 3 (1979): $247-$ 60.

45. Paccia, J. M., and F. Curcio. "Language Processing and Forms of Immediate Echolalia in Autistic Children." J Speech Hear Res 25, no. 1 (1982): 42-7.

46. Fay, W. H. "Mitigated Echolalia of Children." J Speech Hear Res 10, no. 2 (1967): 305-10.

47. Roberts, J. M. "Echolalia and Comprehension in Autistic Children." J Autism Dev Disord 19, no. 2 (1989): 271-81.

48. Prizant, B. M. "Language Acquisition and Communicative Behavior in Autism: Toward an Understanding of the "Whole" of It." J Speech Hear Disord 48, no. 3 (1983): 296-307.

49. Prizant, B. M., and J. F. Duchan. "The Functions of Immediate Echolalia in Autistic Children." J Speech Hear Disord 46, no. 3 (1981): 241-9.

50. Lord, C., M. Rutter, and A. Le Couteur. "Autism Diagnostic Interview-Revised: A Revised Version of a Diagnostic Interview for Caregivers of Individuals with Possible Pervasive Developmental Disorders." J Autism Dev Disord 24, no. 5 (1994): 659-85.

51. Howlin, P. "Can Early Interventions Alter the Course of Autism?" Novartis Found Symp 251 (2003): 250-59; discussion 60-65, 81-97.

52. Wodka, E. L., P. Mathy, and L. Kalb. "Predictors of Phrase and Fluent Speech in Children with Autism and Severe Language Delay." Pediatrics 131, no. 4 (2013): e1128-34.

53. Pickles, A., D. K. Anderson, and C. Lord. "Heterogeneity and Plasticity in the Development of Language: A 17-Year Follow-up of Children Referred Early for Possible Autism." J Child Psychol Psychiatry 55, no. 12 (2014): 1354-62. 
54. Rutter, M., and L. Lockyer. "A Five to Fifteen Year Follow-up Study of Infantile Psychosis. I. Description of Sample." Br J Psychiatry 113, no. 504 (1967): 1169-82.

55. Pickett, E., O. Pullara, J. O'Grady, and B. Gordon. "Speech Acquisition in Older Nonverbal Individuals with Autism: A Review of Features, Methods, and Prognosis." Cogn Behav Neurol 22, no. 1 (2009): 1-21.

56. Windsor, J., S. S. Doyle, and G. M. Siegel. "Language Acquisition after Mutism: A Longitudinal Case Study of Autism." J Speech Hear Res 37, no. 1 (1994): 96-105.

57. Fountain, C., A. S. Winter, and P. S. Bearman. "Six Developmental Trajectories Characterize Children with Autism." Pediatrics 129, no. 5 (2012): E1112-E20.

58. Kanner, L. "The Conception of Wholes and Parts in Early Infantile Autism." American Journal of Psychiatry 108, no. 1 (1951): 23-6.

59. Cobrinik, L. "Unusual Reading Ability in Severely Disturbved Children. Clinical Obserbation and a Retrospective Inquiry." J Autism Child Schizophr 4, no. 2 (1974): 163-75.

60. O'Connor, N., and B. Hermelin. "Two Autistic Savant Readers." J Autism Dev Disord 24, no. 4 (1994): 501-15.

61. Sandbank, M., K. Bottema-Beutel, and T. Woynaroski. "Intervention Recommendations for Children with Autism in Light of a Changing Evidence Base." JAMA Pediatr (2020).

62. Green, J., and S. Garg. "Annual Research Review: The State of Autism Intervention Science: Progress, Target Psychological and Biological Mechanisms and Future Prospects." J Child Psychol Psychiatry 59, no. 4 (2018): 424-43.

63. Brignell, A., K. V. Chenausky, H. Song, J. Zhu, C. Suo, and A. T. Morgan. "Communication Interventions for Autism Spectrum Disorder in Minimally Verbal Children." Cochrane Database Syst Rev 11 (2018): CD012324.

64. Kissine, M., X. Luffin, F. Aiad, M. Bourourou, G. Deliens, and N. Gaddour. "Noncolloquial Arabic in Tunisian Children with Autism Spectrum Disorder: A Possible Instance of Language Acquisition in a Noninteractive Context." Language Learning 69, no. 1 (2018).

65. Mottron, L. "Should We Change Targets and Methods of Early Intervention in Autism, in Favor of a Strengths-Based Education?" Eur Child Adolesc Psychiatry (2017).

66. Dawson, M., I. Soulieres, M. A. Gernsbacher, and L. Mottron. "The Level and Nature of Autistic Intelligence." Psychol Sci 18, no. 8 (2007): 657-62.

67. Norrelgen, F., E. Fernell, M. Eriksson, A. Hedvall, C. Persson, M. Sjolin, C. Gillberg, and L. Kjellmer. "Children with Autism Spectrum Disorders Who Do Not Develop Phrase Speech in the Preschool Years." Autism 19, no. 8 (2015): 934-43.

68. Rose, V., D. Trembath, D. Keen, and J. Paynter. "The Proportion of Minimally Verbal Children with Autism Spectrum Disorder in a Community-Based Early Intervention Programme." J Intellect Disabil Res 60, no. 5 (2016): 464-77.

69. Anderson, D. K., C. Lord, S. Risi, P. S. DiLavore, C. Shulman, A. Thurm, K. Welch, and A. Pickles. "Patterns of Growth in Verbal Abilities among Children with Autism Spectrum Disorder." J Consult Clin Psychol 75, no. 4 (2007): 594-604.

70. Tager-Flusberg, H., and C. Kasari. "Minimally Verbal School-Aged Children with Autism Spectrum Disorder: The Neglected End of the Spectrum." Autism Res 6, no. 6 (2013): 468-78.

71. Klin, A., J.H. Danovitch, A.B. Merz, and F.R. Volkmar. "Circumscribed Interests in Higher Functioning Individuals with Autism Spectrum Disorders: An Exploratory Study." Research \& Practice for Persons with Severe Disabilities 32, no. 2 (2007): 11.

72. Kuhl, P. K. "A New View of Language Acquisition." Proc Natl Acad Sci U S A 97, no. 22 (2000): 11850-7.

73. Hauser, M. D., N. Chomsky, and W. T. Fitch. "The Faculty of Language: What Is It, Who Has It, and How Did It Evolve?" Science 298, no. 5598 (2002): 1569-79. 
74. Blasi, A., S. Lloyd-Fox, V. Sethna, M. J. Brammer, E. Mercure, L. Murray, S. C. Williams, A. Simmons, D. G. Murphy, and M. H. Johnson. "Atypical Processing of Voice Sounds in Infants at Risk for Autism Spectrum Disorder." Cortex 71 (2015): 122-33.

75. Gao, Y., A. Linke, R. J. Jao Keehn, S. Punyamurthula, A. Jahedi, K. Gates, I. Fishman, and R. A. Muller. "The Language Network in Autism: Atypical Functional Connectivity with Default Mode and Visual Regions." Autism Res 12, no. 9 (2019): 1344-55.

76. Emerson, R. W., C. Adams, T. Nishino, H. C. Hazlett, J. J. Wolff, L. Zwaigenbaum, J. N. Constantino, M. D. Shen, M. R. Swanson, J. T. Elison, S. Kandala, A. M. Estes, K. N. Botteron, L. Collins, S. R. Dager, A. C. Evans, G. Gerig, H. Gu, R. C. McKinstry, S. Paterson, R. T. Schultz, M. Styner, Ibis Network, B. L. Schlaggar, J. R. Pruett, Jr., and J. Piven. "Functional Neuroimaging of High-Risk 6-Month-Old Infants Predicts a Diagnosis of Autism at 24 Months of Age." Sci Transl Med 9, no. 393 (2017).

77. Eyler, L. T., K. Pierce, and E. Courchesne. "A Failure of Left Temporal Cortex to Specialize for Language Is an Early Emerging and Fundamental Property of Autism." Brain 135, no. Pt 3 (2012): 949-60.

78. Anderson, J. S., T. J. Druzgal, A. Froehlich, M. B. DuBray, N. Lange, A. L. Alexander, T. Abildskov, J. A. Nielsen, A. N. Cariello, J. R. Cooperrider, E. D. Bigler, and J. E. Lainhart. "Decreased Interhemispheric Functional Connectivity in Autism." Cereb Cortex 21, no. 5 (2011): 1134-46.

79. Barbeau, E. B., D. Klein, I. Soulières, M. Petrides, B. C. Bernhardt, and L Mottron. "Age of Speech Onset in Autism Relates to Structural Connectivity in the Language Network." Cerebral Cortex Communications 1, no. 1 (2020).

80. Samson, F., T. A. Zeffiro, J. Doyon, H. Benali, and L. Mottron. "Speech Acquisition Predicts Regions of Enhanced Cortical Response to Auditory Stimulation in Autism Spectrum Individuals." J Psychiatr Res 68 (2015): 285-92.

81. Gaffrey, M. S., N. M. Kleinhans, F. Haist, N. Akshoomoff, A. Campbell, E. Courchesne, and R. A. Muller. "Atypical [Corrected] Participation of Visual Cortex During Word Processing in Autism: An Fmri Study of Semantic Decision." Neuropsychologia 45, no. 8 (2007): 1672-84.

82. Samson, F., L. Mottron, I. Soulieres, and T. A. Zeffiro. "Enhanced Visual Functioning in Autism: An Ale Meta-Analysis." (2011).

83. Maximo, J. O., and R. K. Kana. "Aberrant "Deep Connectivity" in Autism: A Cortico-Subcortical Functional Connectivity Magnetic Resonance Imaging Study." Autism Res 12, no. 3 (2019): 384400.

84. Hong, S. J., R. Vos de Wael, R. A. I. Bethlehem, S. Lariviere, C. Paquola, S. L. Valk, M. P. Milham, A. Di Martino, D. S. Margulies, J. Smallwood, and B. C. Bernhardt. "Atypical Functional Connectome Hierarchy in Autism." Nat Commun 10, no. 1 (2019): 1022.

85. Kana, R. K., T. A. Keller, V. L. Cherkassky, N. J. Minshew, and M. A. Just. "Sentence Comprehension in Autism: Thinking in Pictures with Decreased Functional Connectivity." Brain 129, no. Pt 9 (2006): 2484-93.

86. Soulieres, I., M. Dawson, F. Samson, E. B. Barbeau, C. P. Sahyoun, G. E. Strangman, T. A. Zeffiro, and L. Mottron. "Enhanced Visual Processing Contributes to Matrix Reasoning in Autism." Hum Brain Mapp 30, no. 12 (2009): 4082-107.

87. Poulin-Lord, M. P., E. B. Barbeau, I. Soulieres, O. Monchi, J. Doyon, H. Benali, and L. Mottron. "Increased Topographical Variability of Task-Related Activation in Perceptive and Motor Associative Regions in Adult Autistics." Neuroimage Clin 4 (2014): 444-53.

88. Mottron, L., P. Duret, S. Mueller, R. D. Moore, B. Forgeot d'Arc, S. Jacquemont, and L. Xiong. "Sex Differences in Brain Plasticity: A New Hypothesis for Sex Ratio Bias in Autism." Mol Autism 6 (2015): 33. 
89. Duret, P., F. Samson, B. Pinsard, E. B. Barbeau, A. Boré, I. Soulières, and L. Mottron. "Gyrification Changes Are Related to Cognitive Strengths in Autism." Neuroimage Clin 20 (2018): 415-23.

90. Collignon, O., M. Lassonde, F. Lepore, D. Bastien, and C. Veraart. "Functional Cerebral Reorganization for Auditory Spatial Processing and Auditory Substitution of Vision in Early Blind Subjects." Cereb Cortex 17, no. 2 (2007): 457-65.

91. Dehaene-Lambertz, G., K. Monzalvo, and S. Dehaene. "The Emergence of the Visual Word Form: Longitudinal Evolution of Category-Specific Ventral Visual Areas During Reading Acquisition." PLoS Biol 16, no. 3 (2018): e2004103.

92. Anderson, M. L. "Neural Reuse: A Fundamental Organizational Principle of the Brain." Behav Brain Sci 33, no. 4 (2010): 245-66; discussion 66-313.

93. Gould, S. J., and E. A. Lloyd. "Individuality and Adaptation across Levels of Selection: How Shall We Name and Generalize the Unit of Darwinism?" Proc Natl Acad Sci U S A 96, no. 21 (1999): 11904-9.

94. Colagè, I., and P. D'Ambrosio. "Exaptation and Neural Reuse: A Research Prerspective in Human Specificity." Antonianum 89, no. (2/3) (2014): 333-58.

95. Anderson, M. L., and M. Penner-Wilger. "Neural Reuse in the Evolution and Development of the Brain: Evidence for Developmental Homology?" Dev Psychobiol 55, no. 1 (2013): 42-51.

96. Clarke, T. K., M. K. Lupton, A. M. Fernandez-Pujals, J. Starr, G. Davies, S. Cox, A. Pattie, D. C. Liewald, L. S. Hall, D. J. Maclntyre, B. H. Smith, L. J. Hocking, S. Padmanabhan, P. A. Thomson, C. Hayward, N. K. Hansell, G. W. Montgomery, S. E. Medland, N. G. Martin, M. J. Wright, D. J. Porteous, I. J. Deary, and A. M. Mclntosh. "Common Polygenic Risk for Autism Spectrum Disorder (Asd) Is Associated with Cognitive Ability in the General Population." Mol Psychiatry 21 , no. 3 (2016): 419-25.

97. Savage, J. E., P. R. Jansen, S. Stringer, K. Watanabe, J. Bryois, C. A. de Leeuw, M. Nagel, S. Awasthi, P. B. Barr, J. R. I. Coleman, K. L. Grasby, A. R. Hammerschlag, J. A. Kaminski, R. Karlsson, E. Krapohl, M. Lam, M. Nygaard, C. A. Reynolds, J. W. Trampush, H. Young, D. Zabaneh, S. Hagg, N. K. Hansell, I. K. Karlsson, S. Linnarsson, G. W. Montgomery, A. B. Munoz-Manchado, E. B. Quinlan, G. Schumann, N. G. Skene, B. T. Webb, T. White, D. E. Arking, D. Avramopoulos, R. M. Bilder, P. Bitsios, K. E. Burdick, T. D. Cannon, O. Chiba-Falek, A. Christoforou, E. T. Cirulli, E. Congdon, A. Corvin, G. Davies, I. J. Deary, P. DeRosse, D. Dickinson, S. Djurovic, G. Donohoe, E. D. Conley, J. G. Eriksson, T. Espeseth, N. A. Freimer, S. Giakoumaki, I. Giegling, M. Gill, D. C. Glahn, A. R. Hariri, A. Hatzimanolis, M. C. Keller, E. Knowles, D. Koltai, B. Konte, J. Lahti, S. Le Hellard, T. Lencz, D. C. Liewald, E. London, A. J. Lundervold, A. K. Malhotra, I. Melle, D. Morris, A. C. Need, W. Ollier, A. Palotie, A. Payton, N. Pendleton, R. A. Poldrack, K. Raikkonen, I. Reinvang, P. Roussos, D. Rujescu, F. W. Sabb, M. A. Scult, O. B. Smeland, N. Smyrnis, J. M. Starr, V. M. Steen, N. C. Stefanis, R. E. Straub, K. Sundet, H. Tiemeier, A. N. Voineskos, D. R. Weinberger, E. Widen, J. Yu, G. Abecasis, O. A. Andreassen, G. Breen, L. Christiansen, B. Debrabant, D. M. Dick, A. Heinz, J. Hjerling-Leffler, M. A. Ikram, K. S. Kendler, N. G. Martin, S. E. Medland, N. L. Pedersen, R. Plomin, T. J. C. Polderman, S. Ripke, S. van der Sluis, P. F. Sullivan, S. I. Vrieze, M. J. Wright, and D. Posthuma. "Genome-Wide Association Meta-Analysis in 269,867 Individuals Identifies New Genetic and Functional Links to Intelligence." Nat Genet 50, no. 7 (2018): 912-19.

98. Pohl, A., W. R. Jones, N. Marrus, Y. Zhang, A. Klin, and J. N. Constantino. "Behavioral Predictors of Autism Recurrence Are Genetically Independent and Influence Social Reciprocity: Evidence That Polygenic Asd Risk Is Mediated by Separable Elements of Developmental Liability." Trans/ Psychiatry 9, no. 1 (2019): 202.

99. Castelbaum, L., C. M. Sylvester, Y. Zhang, Q. Yu, and J. N. Constantino. "On the Nature of Monozygotic Twin Concordance and Discordance for Autistic Trait Severity: A Quantitative Analysis." Behav Genet 50, no. 4 (2020): 263-72. 